\title{
EMPLOYEE MOTIVATION, RECRUITMENT PRACTICES AND BANKS PERFORMANCE IN NIGERIA
}

\author{
Mukarramah Modupe ADEOLA \\ Postgraduate Student, Department of Management, \\ Birmingham Business School, \\ University of Birmigham, United Kingdom. \\ E-mail: dupsyn2007@yahoo.com \\ Sulaimon Olanrewaju ADEBIYI (Ph. D.) \\ Department of Business Administration \\ Olabisi Onabanjo University, \\ PMB 2002. Ago-Iwoye, Ogun State. Nigeria \\ E-mail: lanre18april@gmail.com
}

\begin{abstract}
Many organisations recognizes the use of human resource as a major influence to their success. And with today's competitive environment, it is imperative for organisations to find ways to be more effective and efficient in utilizing their resources so as to improve their general performance. Hence, there is need to recruit and retain highly qualified and motivated employees in order to remain competitive in the unstable environment. This study evaluates the relationship between recruitment practices, employee motivation and their impact on organisational performance focusing on the Nigerian banking industry, with a view to investigating factors that motivate employees of Nigerian banks and the methods banks adopt to motivate their employees. The study also assesses recruitment and selection methods used by Nigerian banks to select effective employees. The study is a cross-sectional in time and the primary data collected from a conveniently selected sample of 60 employees each of the seven selected banks. Face-to-face survey and interview was carried out in order to achieve the research objectives and back up theoretical findings. Using correlation and thematic analysis, the results indicated that there was a strong positive relationship between employee motivation, recruitment practices and organisational performance. Findings from the analysis identified that bank employees are mostly extrinsically motivated; although intrinsic factors also motivate them, it is not as motivating as extrinsic factors. The banks also provide more of extrinsic motivators to increase the performance of their employees. The banks make use of various methods of employee selection, by dividing the methods into stages. In addition, recruiting is mostly undertaken through recruitment agencies or advert placements. The study provides future recommendations that banks in Nigeria should be firmer in their selection processes; this will allow them to identify unsuitable applicants and make room for effective employees who will improve the efficiency of the bank and be motivated. At the same time, this research also suggests that the bank should provide more accessible motivational incentives for its employees in order to boost their performance because unmotivated employees are of no use to any organisation.
\end{abstract}




\section{KEYWORDS}

recruitment, selection, motivation, Nigeria, banks, performance.

\section{INTRODUCTION}

In developed countries and stable economies, most employees will leave their current place of work if they are not satisfied with the job or are not sufficiently motivated and apply to organisations where they feel they will be more motivated and will be more able to develop their cognition and experience. On the other hand, in an unstable economy or in developing countries, people often remain in their current jobs irrespective of the motivation. They may even apply to companies where they have zero experience or knowledge about the job description and even have the fear to move elsewhere, especially when they believe they do not know what is obtainable. In short, they have a fear of the unknown. For this reason, the improvement in performance of organisations based in developing countries is, at times, hindered. This is because it is difficult to find the right person that has the required experience and if the organisation finally finds someone suitable qualified, they must be highly motivated so as to provide a positive impact to the organisation. Hence, it is important to initially select the right skilled personnel that will aid in the organisation's future improvement and also to provide a conducive environment that improves adequate job performance. That is one of the major problems facing the Nigerian banking sector, with commercial banks not following the appropriate recruitment processes and having employees that might not be motivated to perform at work to achieve the bank's goal.

In fact, the Nigerian banking industry has grown over the years with some banks going into strategic alliance, while new banks also emerged. Therefore, the expansion of the industry has prompted fierce competition in the sector, which has resulted in unwarranted employment of people, which leads to an excessive rise in the bank's operating costs. There is also the problem of the appointment of the employees who lack adequate banking experience or knowledge or who even have qualifications for the position being offered to them. This invariably discourages the commercial banks from training their staff, and consequently the overall skill level of the banking industry is affected. Most commercial banks do not follow rigorous employment and interview processes. Some recruitments and selection are based mostly on the director's or sponsor's recommendations made on signed complementary cards and not on academic or professional qualifications or experience in current or previous jobs. In addition, with the issue of unemployment in the country people tend to apply to any organisation no matter what the job description, even if they lack the key talents for the job position they applied for. Often here, the organisation will not have the appropriate selection processes to 'filter out' such individuals.

After employing staff it is essential for the employee to be motivated because it affects his or her performance. Workers' performance levels can be of low standard if they are not highly motivated. Managers are responsible for creating an environment that is conducive for improving performance, so as to induce the right behaviour from employees in the organization. For employees to be highly motivated, "the manger must ensure that working conditions are adequate and the welfare package is attractive to the employees" (Shenkel \& Gardner, 2004). Recently, it is been reported that most Nigerian commercial banks, especially the new generation banks, set goals and profit and liability targets that are far-fetched with a clearly specified condition of either confirmation of appointment or promotion or even getting fired if the target is not achieved. The major problem here is whether the employees are motivated enough to achieve these far-fetched goals and if they are provided with a conducive working environment in which to improve their working ability. 
However, one thing they have failed to realise is that these sorts of issues can hinder the performance of the bank because they are not getting the right people on board and are not providing the right motivation factors for their employees, since the success of an organisation is also determined by its employees. This study sets out to describe the relationship between an employee's motivation and recruitment practices and its effect on the organisation's performance in the Nigerian banking industry.

\section{LITERATURE REVIEW}

\subsection{Introduction}

This section reviews the concept of employee motivation, recruitment practices and organisational performance in the Nigerian banking industry by assessing the various definitions and views from numerous previous studies. The literature looks at the various concepts of employee motivation, recruitment practices and their effect on the organisation's performance and how they are related to each other, with theories used to back the variables up. This section also explores how performance is measured in the Nigerian banking industry.

\subsection{Recruitment and Selection}

In an organisation, the management of human resources involves activities such as recruitment, motivation and the training and development of employees. Therefore, recruitment and selection is part of the management decision-making process, which plays an important role in the organisation's success. This is because choosing the right employees enables organisations to improve their capabilities to achieve strategic goals and be able to handle future challenges.

Recruitment can be considered as a process that brings together a group of candidates that are potentially qualified for the job vacancy provided by the organisation. Breaugh (2008) described recruitment as the "set of activities and processes used to legally obtain a sufficient number of qualified people at the right place and time so that the people and the organisation can select each other for their own short and long term interests". The process of recruitment aims at aligning with the strategy of the organisation to employ the best candidates so as to develop their human resources. Hence, recruitment and the selection process form an essential part of the activities carried out in an organisation.

Dessler (2000) identified that "recruitment and selection has an important role in ensuring workers' performance and positive organisational outcomes". However, Budhwar \& Mellahi (2007) viewed that "even though the two functions are closely connected, each term still requires a separate range of skills and expertise, and may in practice be fulfilled by different staff, for instance the recruitment practice, but not normally the selection decision, at times is outsourced to an agency". Therefore, it is logical to treat each practice separately. Recruitment is the process of creating a group of competent people to apply for a job position in an organisation. Selection, on the other hand, is the process by which the organisation's manager makes use of specific tools to choose from a group of candidates a person or persons whom are likely to succeed in the job, considering the management objectives. To state clear distinctions, recruitment practices offer a group of people that are qualified for selection.

\subsubsection{Recruitment and Selection Methods}

Recruitment methods can be classified into two forms: internal and external forms of recruitment. When an organisation decides that the method of recruitment practice they are using is the internal 
form, the practices includes posting a job vacancy on the notice board and announcing it to employee unions so as to notify and provide room for competition for all the employees eligible for the job position in addition to reviewing the records of employees in order to identify potential candidates for the job position. "Filling a job vacancy from within the organisation has its advantages of elasticity and stimulating preparation for possible transfer or promotion (career progress), increasing the general level of morale, and providing more information about job candidates through analyses of past work within the organisation" (Mudashiru et al., 2013). In spite of this, there are situations when existing employees do not possess the right capabilities for the job position in the organisation and where providing existing employees with appropriate skills might require substantial cost and time. In this case, it is crucial for organisations to introduce new employees with different capabilities for the benefit of the organisation. This can be done through the external recruitment method. The external form of recruitment varies and depends on the category of employees that required. This form of recruitment includes advertising in newspapers, on the radio and television, in magazines and at recruiting agencies, etc. Furthermore, the range of recruitment and selection methods practiced around the world is mostly influenced by national factors and cultures.

For the selection process, there are some popular methods used for the selection of the employee, which include interviews, references, tests and physical examinations, etc. Some other methods for selection are application forms, curriculum vitae, assessments, job trials, job aptitude tests, etc. Moscoso (2000)'s research identified that the selection method that is most popular is the interview. This is probably the most used method in many countries throughout the world in recent times. Budhwar (2000) discovered that there is diversity in the methods used for the recruitment and selection process around the world.

\subsubsection{Recruitment Process}

Breaugh (2008) proposed a model that illustrates the recruitment process and which is shown in Fig. 1 below. The model identifies various numbers of recruitment objectives a manager might have. Some of these recruitment objectives involve the specific number of positions the organisations intend to fill and attracting submissions from various individuals who will perform at a particular level and have a certain retention level.

Figure 1 a model of the recruitment process adopted from Breaugh (2008)

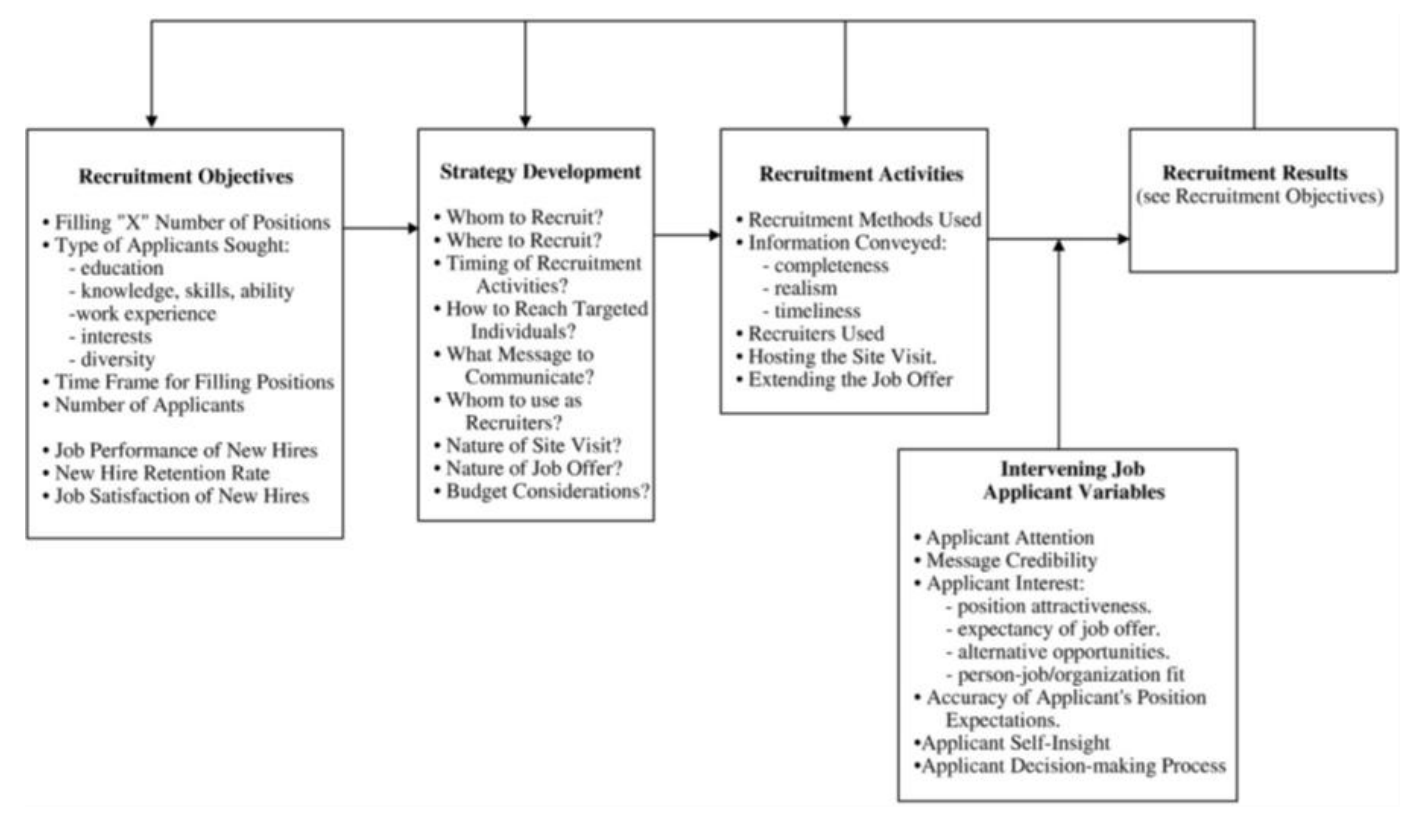


After establishing the recruitment objectives, an organisation must be able to create a rational strategy in order to fill vacant positions. As specified in the model, the manager should concentrate on getting answers related to the established recruitment strategy, which may include who and where to recruit, the time frame of the recruitment process, how to reach the prospective applicants and who to use as recruiters. According to Breaugh (2008), the answers to these strategy-oriented questions should be "consistent with the recruitment objectives previously established". Once the contemplated strategy questions have been answered, the organisation should make sure the recruitment activities are carried out, such as placing an advert of the job opening on job boards such as websites or by hosting receptions at college campuses with all necessary information conveyed. The recruitment result can be viewed as the final stage of the recruitment process. This stage involves an assessment of the recruitment results. More precisely, "an employer should compare its recruitment objectives, that is, what they hope to accomplish and its recruitment outcomes, that is, what they actually accomplished" (Breaugh, 2008). In respect to the job applicant variables shown in the recruitment process model, these variables play an important role in how an employer plans its recruitment process. For instance, if an employer intends attracting the attention of people who are not looking for jobs currently, commonly used recruitment methods such as newspaper advertisements and job fairs may not be particularly efficient. Therefore, the organisation needs accurate information and consideration of the applicant perception for the duration of the recruitment process.

\subsubsection{Recruitment and Selection Practices and Organisational Performance}

Recruitment and selection have become an important tool for organisations in making sure that they have the human capabilities needed to achieve their existing strategic objectives and to continue innovating and developing in the future. Breaugh (2008) supported this by explaining that "good recruitment and selection practices can reduce the risks of failing to achieve the business strategy and of incurring needless costs". A successful recruitment and selection can deliver significant improvements in the efficiency of employee morale and allow the organisation to create a labour force of competent employees who, as a group, offer a better product or service. The likelihood of an organisation's success frequently rests on the capability of the human capital that was recruited and selected. Hence, recruitment and selection practices should be focused on getting the right people, in the right place, at the right time with the right talents to achieve the business objectives.

Ntiamoah et al. (2014) presented a useful summary of the potential positive and negative sides of recruiting and selection by stating that "the recruitment and selection of employees is fundamental to the functioning of an organization, and there are compelling reasons for getting it right". Hence, poor recruitment efforts can lead to poor selection of prospective employees, which can become detrimental to the organisation in the long run. The research of Breaugh et al. (2008) deduced that "poor recruitment decisions continue to affect organisational performance, limit goal achievement and invalidate reward and development strategies which are frequently unfair to the individual employees and can be distressing for the managers also who have to deal with unsuitable employees". Therefore, it is best that great effort is put in to the recruitment and selection practices.

As it is known that recruitment and selection involve getting the best candidate for the job position, it is imperative for the organisation to have an appropriate plan in order to employ the most suitable candidate that has the drive to work in that organisation. Simultaneously, it is important for the organisation to create a favorable environment as well to boost the recruited employees' morale in order to improve their performance. 


\subsection{Employee Motivation}

While having effective employees start from the recruitment and selection process, it is essential to motivate these employees in order to improve their performance and that of the organisations. Motivation has become one of the important aspects in identifying how individuals act the way they do at the workplace. According to Leete (2000), "motivation is the inner drive to behave or act in a certain manner". This inner drive plays an important role in pushing individuals to work towards achieving a specific objective and organisations have recognized it as an important motive towards achieving success in the organisation.

Employee motivation is viewed as "one of the strategies of organisations to enhance its performance through its workers by providing a conducive, motivated environment in the organisation" (Taghipour \& Dejban, 2013). Employee motivation is based on the condition where employees are ready to dedicate time and passion to their work by devising better techniques to get the work done with all sense of eagerness and dedication. According to Shenkel \& Gardner (2004), "motivating employees is sometimes tricky for organisations: if the right environment or motivational factors are not in place it will result in poor performance, inadequate satisfaction, declining morale and widespread discouragement". Amabile (1993) argued that it is essential for "managers and organisations to understand and know how to deal effectively with their employees' motivation since motivated employees are important to ensure the organisation becomes successful". The study also added that unmotivated employees are unlikely to perform well or may even dodge responsibilities at work.

Motivation can be broken up into two major forms: extrinsic and intrinsic motivation. Extrinsic motivation can be viewed as including external factors, which can be determined in monetary terms, such as salary, benefits, promotions and incentives. Amabile (1993) explains that "individuals are extrinsically motivated when they engage in work in order to obtain some goal that is separate from the work itself".

Intrinsic motivation, on the other hand, refers to internal factors such as job satisfaction, responsibility, freedom to act and development of skills and abilities. Individuals that are intrinsically motivated are mostly viewed as self-motivated because "they enjoy performing the actual tasks or the challenge of successfully completing a certain task" (Moshan et al., 2012).

These two different aspects of motivation are connected to each other and cannot be seen in isolation. Amabile (1993) states that both "intrinsic and extrinsic factors can motivate employees to do their work. However, both factors can have very different effects on employees". In the service industry, specifically here the banking sector, embracing employee motivation can be portrayed when an employee only goes to work for no other reason than the salary they receive. However, when an employee is still not satisfied, there is the tendency for them not to be productive. When that happens, it results in a low rate of job commitment and performance, which can affect the organisation in the long run.

\subsection{Organisational Performance}

According to Richard et al. (2009), "organization performance is determined by measuring the actual outputs of an organization against its intended outputs (i.e., goals or objectives)". Barathi \& Kamath (2007) explained that "organization performance comprises three areas of company outcomes, namely, financial performance (return on assets, return on investment, and profits), product market performance (sales and market share), and shareholder return". Many organisations measure their performance through their financial activities while at the same time, some other organisations recognize the non-financial performance measurements, such as management quality, long-term orientation, workforce quality, etc. 
According to Sabo (2008), "a good means of measuring performance in Nigerian banks and other business organisations is through the use of financial analysis, which was described as the process of identifying the financial strengths and weaknesses of the organisation by properly establishing the relationship between the details of the balance sheet, the profit and loss account". The financial analysis evaluates the bank's performance in terms of, for example, asset quality, profitability and solvency. The financial statements are prepared to provide overall information on the organisation on a regular basis, mostly annually.

However, in this study, the bank's performance will be examined through workforce qualities and financial output (profit and cash flows). In this sense, it is the main concern of the bank is to ensure that the right recruitment and selection practices are used to bring in the right people on board and provide appropriate motivational tools that stimulates and improves employee's morale for better performance and improve quality of service.

\subsection{Recruitment Practices, Employee Motivation and Bank’s Performance}

From the above explanations, it can be deduced that recruitment practices and employee motivation are of individual importance to any organisation's performance. However, it is has not been realized that both recruitment practices and employee motivation can be connected in order to improve organisational performance. Employee motivation starts from the initial job application and how prospective applicants perceive the whole process of recruitment. The morale of these applicants can influence their job performance positively or negatively, if they are eventually employed. For that reason, banks should endeavor to have an effective recruitment process for the prospective applicants to have a clear view about the vacant job position and, at the same time, providing necessary motivational packages that will benefit the employees in order to improve their job performance and achieve organisational goals. This is because having effective employees is a vital factor for any organisation to perform efficiently, and survive in the changing business environment.

In general, when recruiting potential candidates, it is important to highlight the job description and features that make the position desirable and provide a clear vision of future possibilities. It is also important to recruit employees who are genuinely driven and enthusiastic about the job position. There is also the need to understand the potential employee's set of unique motivational drivers because it is absolutely crucial to the effectiveness of the recruitment and selection process, and which will significantly improve any human resource team's ability to select the right person for the job and the organisation as a whole. By effectively recruiting and selecting the right employee, it can be less complicated to motivate and retain employees. For employees to be motivated, Moshan et al. (2012) viewed that "sales recruiting minimums must be upheld" such as pay, working conditions and job security. Without the basics, recruiting even the best employee might be challenging.

Hence, with the enlightenments of all the research concepts, it can be concluded that, irrespective of any employee, the appropriate recruitment and motivational foundation will keep them engaged in their work. This will therefore result in a positive relationship between employee's motivation, recruitment practices and organisational performance.

\section{METHODOLOGY}

This research was achieved by making use of both quantitative and qualitative methods of research. It focuses on commercial banks in Lagos, Nigeria. The chosen sample population of the study is the 
employees of both old and new generation banks. The banks are; Access bank Plc, First bank Plc, United bank for Africa (UBA), Guarantee bank Plc, Sterling bank Plc, First City Monument bank Plc (FCMB), and Zenith Bank Plc. These banks have diverse range of employees which made them most suitable for the study. The sampling technique used in this study is the random sampling method. The random sampling method provides all the employees of the banks an equal chance of being selected for the survey since all the employees have gone through the recruitment process and have experienced motivation issues at one point or another. This research made use of the questionnaire, which was administered through a face-to-face approach, handed directly to the respondents by the researchers' and assistance of four trained research assistant, which gave the researchers` the privilege to introduce the topic and offer encouragement to banks employees in answering the questionnaire. A total of sixty (60) copies each of the questionnaires were administered in each of the seven selected banks branches in Lagos, totaling 420 questionnaires. Out of the total 420 questionnaires administered across the seven banks, 385 representing 91.67\% were returned and properly filled for the purpose of data analysis. The questionnaire used in this research asked both open-ended and closed questions because the closed questions allow respondents to select from a range of prearranged answers while open-ended questions will allow the respondents have a free narrative for their response. The survey questionnaire consisted of three sections. The first section dealt with the personal and demographic characteristics of the respondents, which were expected to identify the respondents' job position, level and duties. The questions asked in the second section are related to the recruitment and selection practices and organisational performance of the bank and the employee's perception of it. This section consisted of both open-ended and closed questions to expand on the participants' response and which included a five-point Likert scale from 'strongly agree' to 'strongly disagree'. The third section asked questions pertaining to employee motivation and the identification of factors that motivates employees of the bank. The questions also took a form of five-point Likert scales from 'strongly agree' to 'strongly disagree' so as to allow the respondents to provide their views in measurements of how motivation affects them. The questions were clear and precise in order for easy completion by the busy employees. The qualitative method that was applied is the interview method, which involved one-on-one question and answer sessions between the researchers and some heads of section of bank branches. The selected banks supervisors were interviewed so as to have their own perspective of the subject matter. The interview meeting was carried out in the staffs' respective offices at their own convenient time. There was an in-depth interview with five employees each of selected banks from the manager to the supervisors to the head of Human resources. To analyse the data, different techniques were implemented. For the quantitative data analysis, descriptive statistics were used including frequency counts and percentages, and the mean of the responses were calculated for each of the variables in all the sections. The descriptive statistic measures were used to create a summary of the respondents' demographic characteristics and, as a result, a frequency analysis was conducted on the research objectives. Correlation was calculated to show whether there is significant relationship or not between all the variables (recruitment practices, employee motivation and banks performance) related to the subject on the basis of the research objectives. These analyses were achieved with the use of SPSS Package.

\section{RESULTS AND DISCUSSION}

\subsection{Quantitative Data Analysis}

\subsubsection{Presentation and Analysis of Demographic Data}

For the demographic data, questions were asked on the respondents' gender, qualifications, number of years worked at the bank, work level and position at the bank and the core duties they perform at work. This is fully illustrated in appendix. With regards to the employee's gender, it was observed 
from the result that $49.1 \%$ of the respondents were male while $50.9 \%$ were female in this category of employees. This shows that there were a few more female participants than male in this survey. This can be a result of the sampling technique used or that the bank might have more female staff than male. Identifying the highest qualification of the respondents revealed that over $50 \%$ of the respondents hold a $1^{\text {st }}$ degree from different areas. Hence, it is observed that the banks have various levels of qualified personnel to aid in carrying out their objectives. Results gathered from the data collected also showed $55.5 \%$ of the employees have worked with the banks between one and six years. Most of the respondents are medium level workers, with $52.7 \%$ of the employees consisting of sales executives, relationship managers, operation managers, etc. Meanwhile, $31.8 \%$ of the respondents are low level employees with various personnel functions such as cash teller officers, customer service officials, etc. Finally, $15.5 \%$ of the respondents are high level employees such as supervisors and HR heads, etc. This shows that the survey covered all the job levels in the banks and provided different views of how job level influenced the responses to the survey.

\subsubsection{Presentation and Analysis of Data According to the Research Variables}

To achieve the stated objectives, some questions were asked and the responses were analysed in relation to the objectives the survey wanted to achieve. In order to identify the different methods used in recruiting employees, questions were asked on how the employees found out about the job position. Some $30.4 \%$ of the respondents stated that they found out through other methods of recruitment such as employee referrals, the use of family and friends and internal sources of recruitment, whereby existing employees are considered when a vacant position is available. In relation to the recruitment practices, respondents were asked if there are any methods considered most for the selection of employees. Around $46.4 \%$ of respondents agreed that all the methods for selection are very important and are all considered by the bank as conditions for recruitment and selection of new employees.

Results from the data collected from the employees showed that $85.5 \%$ of the respondents pointed out that their morale affected their job application. Where questions were asked about whether the job description and specifications were clearly defined in the recruitment process, it was clear that the respondents expressed their views towards the job description being clearly stated during the recruitment process, with $77.5 \%$ agreeing to it. As such, it is reasonable to infer that employees were clearly provided with the job description and specifications before starting the job. The findings revealed that the respondents had mixed opinions on whether the job position they were given was what they were expecting. A total of $67.5 \%$ agreed to this fact while $17.2 \%$ disagreed, implying that the job position they were put in was not what they wanted. From the distribution, it is observed that most respondents agree to the opinion that the recruitment and selection process influenced performance at work, with the total of $66.5 \%$. This shows that some respondents have been able to perform their duties because of the recruitment and selection method the bank used, as it has added to their knowledge of performing better at work. In addition, respondents shared their opinions about the recruitment and selection practices of the bank, which many viewed to be very effective and professional while suggesting there is still room for future changes and improvements. The survey shows that the majority of the respondents believe to be a competent addition to the bank's performance, with $98.2 \%$ agreeing. This is high enough to deduce that employees feel they have a vital impact on the bank and its performance.

In connection to the competency of the employees, respondents were asked if the job position they currently hold allows them to make use of their full potential. The responses show that there were mixed views about the employees and the positions they hold in terms of whether they perform well in it. Some $91.9 \%$ agreed that their job position allows them to make use of their full potential, while the remainder disagreed, suggesting that the job position is hindering them from showing their full potential. 
The survey data also indicates that many respondents feel motivated at work, with a total of $70.9 \%$ agreeing to the statement. This indicates that some employees still feel highly motivated regardless of the problems or situations they find themselves in at work. In order to identify how good the bank's performance is at present, respondents were asked if the bank's performance is outstanding. Some $90.9 \%$ of the respondents agreed that the bank's performance has been tremendous over the years, with the increase in customer base and profit.

To identify factors that motivate the employees of banks, some questions were asked about various motivational factors that can influence them as employees of a bank. Some $95.6 \%$ respondents agreed that they are motivated to perform more at work when the incentive is financial in nature. Exploring further on the specific financial incentive that motivates employees, $98.2 \%$ of the respondents identified that salary and its subsequent increments (when provided) motivate them to achieve their specified target. When asked whether the benefit packages the employees receive motivates them, $96.4 \%$ respondents agreed that the benefit packages they receive motivate them to do their best at work.

Furthermore, many respondents were of the view that the possibility of them getting promoted to a higher level motivates them to work hard at the bank, with a response rate of $96.6 \%$ in agreement. Some $98.4 \%$ of the participants were of the view that a proper working condition motivates them to do their best work. Meanwhile $92.7 \%$ of the respondents agreed that being credited and recognized for the work they perform in the banks, motivates them to improve in their performance. The survey also gathered that the drive of gaining more skills at the job motivates many employees, which was shown with a $99.2 \%$ response rate. In addition, $82.1 \%$ respondents were in agreement that their desire to work at banks motivates them to work hard and improve their performance so as to retain their job in the bank. However, there were mixed views when a question surfaced on whether the employees are motivated by non-financial incentives.

In fact, $67.3 \%$ of the respondents agreed that non-financial incentives motivate them to perform well at work. Finally, a question was asked on whether the employees were satisfied with the motivation packages and incentives they receive from the bank. Only 52\% of the respondents agreed that they were satisfied with the motivational packages the bank provides for them, while $15.4 \%$ disagreed, suggesting they were not nearly satisfied enough with the incentives they receive at work. Therefore, this survey revealed that most of the respondents are financially motivated, especially with their salaries and the subsequent increases, which was further explained during the interview session. Although it was also identified that other factors motivate the employee to increase their performance and achieve their stated targets at work.

\subsubsection{Reliability Test}

When choosing scales, it is important to include scales that are reliable. Hence the scales need to be tested so as to evaluate the amount of regularity between different measurements of variables. Cronbach's Alpha was used to test the reliability and to assess the regularities of the entire scale. Nunnally (1978) indicated that reliability scores greater than 0.70 are an acceptable reliability coefficient but "lower threshold are sometimes used in the literature". Cronbach's Alpha was computed for the following measures of the variables in this study: factors that influence employee motivation and recruitment and performance. The reliability test was computed using SPSS.

As the first variable was recruitment and performance, seven items were computed to check the reliability statistics and that the results (appendix) exceed the acceptable score which is 0.7 . Here, Cronbach's Alpha score was 0.736 . Therefore, the instrument used for this study had satisfactory construct validity. 
The second variable is employee motivation and its factors. Eleven items where entered to confirm the reliability result. The Cronbach's Alpha score was 0.707 , which is acceptable according to the above standard guideline (appendix). Therefore, it can be viewed that the entire variable scale of this survey exhibited a good internal reliability and satisfactory construct validity.

\subsubsection{Test of Hypothesis}

To test the hypothesis of employee motivation, recruitment process and organisational performance, some items stood as characteristics of each variable. However, the items were then transformed into new variables to represent the dependent and independent variables. Thus, it was easier to identify the effect of one on the other and to establish whether there is a positive or negative correlation between the variables. After looking at the correlation table (appendix 5), the result shows that there is a positive relationship between the dependent variable, organisational performance, and the independent variables: employee motivation and recruitment practices (0.590). This shows a strong correlation between the dependent variable and the independent variables since the $\mathrm{p}$-value is less than 0.01 Alpha $(0.000<0.01)$, which is significant at $1 \%$. We thus accept that employee motivation and recruitment practices have a significant and positive relationship with the bank's performance. In order to expand more on the responses gathered from the survey, an interview was conducted for the high level staff of Banks to share their opinions about the research concept.

\subsection{Qualitative Data Analysis}

There were three major themes identified from the data gathered, namely, recruitment and selection practices, employee motivation and performance measurement, which still had their respective subthemes. These themes were identified as influential to the banks`effectiveness.

\subsubsection{Employees' Perception of Recruitment and Selection Practices}

Respondents were asked to assess the bank's recruitment and selection practices. It was acknowledged that banks`recruitment and selection practice is efficient, because they ensure the selection process is thorough. As one employee said, "it is important to get the right people for the right position, therefore the bank has stated the requirements to be met before being employed". For the recruitment and selection process, many employees held that prospective applicants need necessary educational qualifications and the right experience for them to qualify for the specific vacant job position.

The major methods the bank adopts for recruitment are recruitment agencies and the internet and newspaper adverts, which have proved to be effective. For the selection method, the HR head stated that because the bank wants to be thorough, the prospective candidates go through various stages of the selection process before the most suitable candidate for the job is chosen. The selection process begins from the applicants submitting their curriculum vitae (CV) and attaching the right documents with it, then, after the preliminary stage, shortlisted applicants who meet the bank's requirements will be called in for a test and a follow-up interview designed to ascertain whether the applicant is of sound mind and of good character. Then the eligible candidates will go through training to be able to have an idea of the position they are applying for. Afterwards, the right candidate will be employed.

While this seems to be an efficient recruitment and selection practice, some employees still had reservations about it, by identifying that the recruitment and selections practices have their flaws. From the survey carried out, the majority of the employees were recruited from referrals, personal relationships or internal recruitment. Just a few of the respondents were recruited through the methods the bank actually claims to adopt. An employee mentioned that when it comes to recruiting 
employees through referrals and personal relationships, it tends to lead to favoritism because those kinds of applicants do not mostly go through all the stages of the selection process. This might lead to employing individuals without key talents that will increase the bank's performance and demotivating other employees who feel they were not provided that kind of easy opportunity. Another employee's view was that there is beginning to be lack of 'key talents' to recruit, which is an issue for the bank. However, with these challenges there were also future improvement plans such as 'the procedure for selection of potential employees should be strictly adhered to'. In other words, the bank's job requirements and related experience should be implemented. There should also be the adoption of doing adequate background checks on prospective employees; educational qualifications and experience should not be solely relied on.

Views were also shared on the impact recruitment and selection has on performance. Many employees stated how important recruitment and selection is because it immensely impacts performance. An employee said the recruitment of new employees helps to demonstrate the bank's ambitions by emphasizing the skills to which it attaches the highest priority.

\subsubsection{Employees' Perception of Motivation}

One employee said "there is so much effort put in motivating the employees from short to long term benefits". The essence of motivating the employees is to ensure continuous survival of the bank operations. The bank tries to make sure the motivation packages adopted cover all areas of motivation of employees. Such packages include salaries, working reward benefits, bonuses, fringe benefits, loan schemes, promotion, training, good working conditions, opportunity to use and develop their skills and providing freedom to act. Many of the respondents were of the view that most employees are financially motivated with salaries and bonuses, which was also observed in the survey carried out. This is because with the boost of extra bonuses, they will be able to achieve the branch's target and improve overall bank performance. Another employee mentioned how "these benefits are renewed every two years by the meeting of unions, management and the board of directors".

Regarding these benefits however, one employee was asked about motivation issues in the branch and replied by stating that "some people do nothing while others do so much which discourages me because they get paid to do nothing while one that does so much might not get paid as much as other people". Other employees viewed that appropriate recognition is not given to the subordinate staff that work very hard; rather recognition is just given to the bosses. There was also an issue that came up concerning some motivational packages not being provided to all levels in the bank.

A supervisor said employees that work as DSAs are not included in the loan schemes and fringe benefits, which can cause low morale for them. Another employee mentioned that the time frame for working before being eligible for some benefits is outrageous, leaving employees to either leave the bank or not perform properly. Nonetheless, there are plans for further improvement of the motivation packages, such as the introduction of yearly recognition and awards for individual employees and branches with outstanding performances, a more flexible loan scheme and making some benefits more accessible.

Employees also spoke about how motivation impacts performance, indicating they understand that in order to be effective, employees needs to perform well and that motivation affects the bank's performance. Low morale is bad for the bank and should be avoided as much as possible because it is unhealthy for a work environment and the overall corporate performance. When further asked about the connections recruitment and motivation have and how it impacts on the bank's performance, the HR manager mentioned how "the bank can only succeed if we recruit and motivate people who are able to respond and adjust to the challenges of the future". Therefore, there 
is a need to bring in the right people into the bank because the right employee will not be difficult to motivate and will be able to perform diligently for the banks.

\subsubsection{Employees' Perception of Performance Measurement}

The bank's performance is very important because it is under the scrutinizing eye of the governing bodies and, if they perform poorly, this will affect their whole operation from customers to staff. To be efficient, the bank assesses their performance as a whole and that of their employees. For the employees, performance is measured mostly by a quarterly performance appraisal which involves reviewing and evaluating the employee's career development and performance reflections. The performance appraisal draws attention to the employee's productivity, accomplishments and whether they are meeting the bank's target. As for measuring the bank's overall performance, many employees commented that the performance is measured using key performance indicators (KPL) and the amount of money they bring in. That is, making a profit and being able to meet their target. There were also comments on the importance of these performance measurements. One employee said the bank's performance measurements help detects strengths, weaknesses and provides room for potential future improvements for the bank.

\section{DISCUSSION OF FINDINGS}

Relating the findings gathered from the research to relevant literatures, recruitment practices and employee motivation has always been stressed by various scholars to result in efficiency of both employees and organisations. From the research findings, it was identified that it is the responsibility of the bank's management to recruit suitable employees and motivate their employees in order to provide ground for improved performance within the employees and for the bank (Begum, Zehou, \& Hossain Sarker., 2014).

The research findings discovered that banks in Nigeria have a structured way of selecting new employees. The first stage is recruiting potential applicants that have all the necessary requirements for the vacant job position through various medium of recruitment. Shortlisted applicants are then invited for a test and follow-up interview to select the suitable candidate. From the interview, it was realized that some respondents were of the opinion that recruitment and selection practices adopted by the bank were very effective as the right capabilities are always employed. However, some other employees were of the view that the measures adopted for recruitment and selection were not effective and the reasons raised included favoritism and lack of key talents in Nigeria.

Recruitment as a human resource management function, is one of the activities that influences the performance of any organisation (Brindusoiu, 2013). This is because it has been understood that poor recruitment practices will continue to affect organisational performance and hinder goal achievement. This study revealed that recruitment and selection practices have improved the performance of the employees and the bank. Recruitment and selection practices had led to the employment of qualified employees, while there were still reservations that recruitment and selection practices alone cannot improve the performance of the bank because the bank might not be applying these methods appropriately which is where motivation comes in place.

From the data gathered, employees have different needs to be achieved and these needs influences how they perform at work. When these needs are achieved, it prompts another desire to achieve another necessity which is in accordance with Maslow's hierarchy of needs. From the findings, financial incentives such as salaries and its subsequent increase provided for employees will increase their motivation for better performance which is emphasized by Maslow's basic needs. It was also gathered that majority of the employees are permanent workers which provides possibility 
for promotion at work. This tends to enhance the frame of mind of employees when it comes to job security and increase their performance at work. This explains Maslow's safety needs. These findings are also associated to the expectancy theory (Amabile, 1993).

The belonging needs of employees which can be as a result of good working environment was identified to give rise to higher motivation at work. In addition, allowing employees make full of their potentials and abilities will increase the employees' motivation at work. The utilization of employees' abilities and valuing their services at work further justifies the theoretical understanding of esteem needs proposed by Maslow. Some employees are motivated when they fulfil the desire to meet the bank's target in order to be retained in the banks. While other employees are motivated when they have the drive to gain more skills by taking up challenging task. This sense of fulfilment and achievement identified from the findings above explains Maslow's theoretical assumption of the self-actualization needs. Also, the findings above can also be connected to the Herzberg motivator factor (Herzberg et al., 1959). Besides, employees still believe that financial incentives will motivate them more at work than other incentives. When employees are appraised appropriately once they perform well at work, it motivates them to have a better performance. Therefore, these research findings are supported by the theoretical assumptions of Herzberg's hygiene factors. If the hygiene factors are not fulfilled it will lead to dissatisfaction of employees.

Therefore, banks would be advised to bear in mind that their employees are vital to the enhancement of the bank's performance and great attention needs to be provided in getting the employees with right capabilities and motivating them appropriately in order to improve the bank's efficiency. Hence, better performance can be achieved by banks through adopting both appropriate recruitment methods, selection criteria and motivation methods.

\section{Summary of Findings}

The major objective of this research was to examine the relationship between employee's motivation, recruitment practices and organisational performance in theory and practice. To accomplish that, the research captured a number of important aspects with the support of previous findings on how recruitment practices and employee motivation affects the organisational performance, especially in the Nigerian banking industry. Begum et al., (2014) state that "knowing what qualities to look for and what questions to ask, can help in making the recruitment and selection process more effective and at the same time booster the motivation of an employee". This study also identified that effective recruitment practices and employee motivation can be linked together to increase the performance of both employees and the organisation as a whole. From the research gathered, an employee's motivation starts from how effective the recruitment process is carried out before being employed and then from the organisation providing a conducive environment for the employees to perform in order to achieve the organisational goals. Recruitment practices and employee motivation are very important for the success of any organisation. Having employees with suitable capabilities that fit the organisation's objectives and have the willingness to perform well in their position mostly depends on the combination of the organisation's recruitment and selection practices and the motivation methods the organisation adopts.

The study highlighted various recruitment and selection methods adopted by the selected banks of study, which they find effective in achieving their objectives. These included recruitment agencies, newspaper adverts, tests and interviews. However, it was found that there are some recruitment methods used by the bank that may hinder the bank's performance, which includes employment through employee referrals and personal relationships (family and friends). These methods were identified as leading to the recruitment of employees that may not have the appropriate capabilities for the job position given, which can negatively influence the morale of the employees, their performance and that of the banks. 
The study also discovered factors that motivate employees and what methods the banks adopt to motivate their employees in order to achieve their performance targets. The bank makes sure their employees are highly motivated in order to bring the best out of them. They provide necessary provisions to boost the employees' performances, such as good working conditions, good salaries and bonuses, promotion and other benefits. It was also identified that employees are mostly motivated by extrinsic factors, especially those with financial incentives. Nonetheless, it was realized that financial incentives alone are not, to an extent, sufficient to motivate employees to perform well at work. Other factors that motivate employees are good working conditions, the drive to gain more skills, achieving recognition, etc.

This study also gave an opportunity to banks in Nigeria to address the recruitment practices and employee motivation challenges as they seek to improve on their performance.

\section{CONCLUSION}

This section brings together the research outcome and knowledge gathered from the study with future recommendations for the selected bank of study. The project aimed at executing research on how to increase performance through implementing effective recruitment practices and employee motivation. With an in-depth review of the relevant literature, the interviews and survey conducted in this study showed there was a practical link between the theoretical assumptions and the practical views on how employees can best be motivated and recruited for better performance levels in organisations. This shows a more realistic understanding of employees' opinions on recruitment practices and motivation and how these affect performance within the case study in question. Therefore, it is concluded that employee motivation and recruitment practices have, to a large extent, an impact on the performance of an organisation and it is vital to understand this if the organisation wants to achieve their stated goals.

\section{LIMITATIONS AND RECOMMENDATIONS}

From the above findings, it is realized that recruitment and selection practices and employee motivation is very important and connected to the performance of any organisation, whether this is a bank or not. However this study also had its limitations and future recommendations.

For the limitations, since the study focuses only on Nigerian banks, the findings cannot be assumed for banks in other African countries or around the world.

It cannot be presumed that recruitment and motivation in relation to performance is the same in other business sectors in Nigeria or around the world.

As for recommendations, the following were formulated to help improve the banks` future effectiveness:

(i) All prospective applicants should be given equal and fair chance during the recruitment and selection process, preventing favoritism while providing this fair chance. Therefore, 'short-cutting' in the selection process for applicants should be stopped because at times these applicants might not have a positive impact on the bank's performance.

(ii) During the recruitment and selection process, the bank should endeavour that the job position is described and specified in detail in order to filter out unwanted applicants and also to improve the morale of all prospective candidates by ensuring they know exactly what they are getting into.

(iii) There should be annual seminars and training for the employees to refresh their knowledge about the competitive market. Since it is believed that key talents are hard to come by, the bank needs to improve their employees' skills in fields in which they have difficulties in terms of recruitment. 
(iv)The human resource department should improve on the ways of valuing and providing necessary recognition to the employees in order to bring out the best in them and improve their performance.

(v) The motivational packages provided by the bank should be more accessible and flexible. This could include elastic loan schemes and reachable benefits for all levels of employees so as to show that the management has genuine interest in the welfare of their employees.

\section{REFERENCES}

Amabile, T. (1993). Motivational synergy: Toward new conceptualizations of intrinsic and extrinsic motivation in the workplace. Human Resource Management Review, 3(3), 185-201.

Begum, S., Zehou, S. \& Hossain Sarker, M. (2014). Investigating the relationship between recruitment and selection practice and OCB dimensions of Commercial Banks in China. International Journal of Academic Research in Management, 3(2), 146-156.

Breaugh, J. (2008). Employee recruitment: Current knowledge and important areas for future research. Human Resource Management Review, 18(3), 103-118

Breaugh, J. A., Macan, T. H., \& Grambow, D. M. (2008). Employee recruitment: Current knowledge and directions for future research. In G. P. Hodgkinson \& J. K. Ford (Eds.), International Review of Industrial and Organizational Psychology, 23. (45-82)New York: John Wiley \& Sons.

Brindusoiu, C. (2013). Recruitment and selection in services organizations in Romania. Procedia Social and Behavioral Sciences, 92, 112-116.

Budhwar, P. (2000). Evaluating levels of strategic integration and devolvement of human resource management in the UK. Personnel Review, 29(2), 141-157.

Budhwar, P. \& Mellahi, K. (2007). Introduction: human resource management in the Middle East. The International Journal of Human Resource Management, 18(1), 2-10.

Dessler, G. (2000). Human Resource Management. 8th ed. Upper Saddle River, New Jersey: Prentice Hall Incorporated.

Herzberg, F. (1959). The motivation to work. New York: Wiley.

Leete, L. (2000). Wage equity and employee motivation in nonprofit and for-profit organizations. Journal of Economic Behavior \& Organization, 43(4), 423-446.

Moscoso, S. (2000). Selection Interview: A review of validity evidence, adverse impact and applicant reactions. International Journal of Selection and Assessment, 8(4), 237-247.

Mustapha, M., O., Ilesanmi, O. A \& Aremu, M. (2013). The impacts of well-planned recruitment and selection process on corporate performance in Nigerian banking industry (A case study of First Bank Plc (2004-2011). International Journal of Academic Research in Business and Social Sciences, 3(9). 633 648.

Ntiamoah, E., Abrokwah, E., Agyei-Sakyi, M., Opoku, B. \& Siaw, A. (2014). An investigation into recruitment and selection practices and organizational performance. International Journal of Economics, Commerce and Management, 2(11), 1-11.

Nunally, J. (1978). Psychometric theory. 2nd ed. New York: McGraw Hill.

Shenkel, R. \& Gardner, C. (2004). "Five ways to retain good staff", Family Practice Management, Nov-Dec, 57-59.

Taghipour, A. \& Dejban, R. (2013). Job performance: Mediate mechanism of work motivation. Procedia - Social and Behavioral Sciences, 84, 1601-1605. 
SPSS DATA OUTPUT

1.

Gender

\begin{tabular}{|ll|l|l|l|l|}
\hline & Frequency & Percent & Valid Percent & Cumulative Percent \\
\hline Valid & male & 189 & 49.1 & 49.1 & 49.1 \\
& female & 196 & 50.9 & 50.9 & 100.0 \\
& Total & 385 & 100.0 & 100.0 & \\
\hline
\end{tabular}

\section{Qualifications}

\begin{tabular}{|ll|l|l|l|l|}
\hline & Frequency & Percent & Valid Percent & Cumulative Percent \\
\hline Valid & HND & 35 & 9.1 & 9.1 & 9.1 \\
& 1st degree & 193 & 50.1 & 50.1 & 59.2 \\
2nd degree & 112 & 29.1 & 29.1 & 88.3 \\
others & 45 & 11.7 & 11.7 & 100.0 \\
Total & 385 & 100.0 & 100.0 & \\
\hline
\end{tabular}

The duration of working at the bank

\begin{tabular}{|ll|l|l|l|l|}
\hline & & & & Cumulative \\
& Frequency & Percent & Valid Percent & Percent \\
\hline Valid & less than 1 year & 116 & 30.1 & 30.1 & 30.1 \\
& 1-6 years & 214 & 55.6 & 55.6 & 85.7 \\
7-12years & 55 & 14.3 & 14.3 & 100.0 \\
Total & 385 & 100.0 & 100.0 & \\
\hline
\end{tabular}

Work level

\begin{tabular}{|ll|l|l|l|l|}
\hline & & & & Cumulative \\
& & Frequency & Percent & Valid Percent & Percent \\
\hline Valid & low level & 123 & 32 & 32 & 32 \\
& medium level & 203 & 52.7 & 52.7 & 84.7 \\
& high level & 59 & 15.3 & 15.3 & 100.0 \\
& Total & 385 & 100.0 & 100.0 & \\
\hline
\end{tabular}

Methods of Recruitment

\begin{tabular}{|ll|l|l|l|l|}
\hline & & & & Cumulative \\
& & Frequency & Percent & Valid Percent & Percent \\
\hline Valid & radio advert & 18 & 4.7 & 4.7 & 4.7 \\
& TV advert & 25 & 6.5 & 6.5 & 11.2 \\
& newspaper advert & 53 & 13.8 & 13.8 & 25 \\
& professional associations & 81 & 21 & 21 & 46 \\
recruitment agencies & 91 & 23.6 & 23.6 & 69.6
\end{tabular}




\begin{tabular}{|l|l|l|l|l|}
\hline others & 117 & 30.4 & 30.4 & 100.0 \\
Total & 385 & 100.0 & 100.0 & \\
\hline
\end{tabular}

Method most considered for recruitment and selection

\begin{tabular}{|c|c|c|c|c|c|}
\hline & & Frequency & Percent & Valid Percent & $\begin{array}{l}\text { Cumulative } \\
\text { Percent }\end{array}$ \\
\hline \multirow[t]{7}{*}{ Valid } & academic qualifications & 95 & 24.7 & 24.7 & 24.7 \\
\hline & work experience & 67 & 17.4 & 17.4 & 42.1 \\
\hline & interview & 35 & 9.1 & 9.1 & 51.2 \\
\hline & test & 7 & 1.8 & 1.8 & 53 \\
\hline & All of the above & 179 & 46.5 & 46.5 & 99.5 \\
\hline & others & 2 & .5 & .5 & 100.0 \\
\hline & Total & 385 & 100.0 & 100.0 & \\
\hline
\end{tabular}

Morale affects the job application

\begin{tabular}{|ll|l|l|l|l|}
\hline & & & & Cumulative \\
& Frequency & Percent & Valid Percent & Percent \\
\hline Valid & Yes & 329 & 85.5 & 85.5 & 85.5 \\
& No & 11 & 2.8 & 2.8 & 88.3 \\
& Maybe & 45 & 11.7 & 11.7 & 100.0 \\
Total & 385 & 100.0 & 100.0 & \\
\hline
\end{tabular}

The job description and specifications were clearly defined in the recruitment process

\begin{tabular}{|ll|l|l|l|l|}
\hline & & & & Cumulative \\
& & Frequency & Percent & Valid Percent & Percent \\
\hline Valid & strongly agree & 56 & 14.6 & 14.6 & 14.6 \\
& agree & 242 & 62.9 & 62.9 & 77.5 \\
& neutral & 39 & 10.1 & 10.1 & 87.6 \\
& disagree & 46 & 11.9 & 11.9 & 99.5 \\
& strongly disagree & 2 & .5 & .5 & 100.0 \\
Total & 385 & 100.0 & 100.0 & \\
\hline
\end{tabular}

The job position was what I expected

\begin{tabular}{|ll|l|l|l|l|}
\hline & & & & Cumulative \\
& & Frequency & Percent & Valid Percent & Percent \\
\hline Valid & strongly agree & 39 & 10.1 & 10.1 & 10.1 \\
& agree & 221 & 57.4 & 57.4 & 67.5 \\
& neutral & 60 & 15.6 & 15.6 & 83.1 \\
& disagree & 56 & 14.6 & 14.6 & 97.7 \\
strongly disagree & 9 & 2.3 & 2.3 & 100.0 \\
Total & 385 & 100.0 & 100.0 & \\
\hline
\end{tabular}

The recruitment process and selection influenced my performance at work

\begin{tabular}{|l|l|l|l|l|}
\hline & Frequency & Percent & Valid Percent & $\begin{array}{l}\text { Cumulative } \\
\text { Percent }\end{array}$ \\
\hline
\end{tabular}




\begin{tabular}{|ll|l|l|l|l|}
\hline Valid & strongly agree & 53 & 13.8 & 13.8 & 13.8 \\
& agree & 203 & 52.7 & 52.7 & 66.5 \\
& neutral & 95 & 24.7 & 24.7 & 91.2 \\
disagree & 28 & 7.3 & 7.3 & 98.5 \\
strongly disagree & 6 & 1.5 & 1.5 & 100.0 \\
Total & 385 & 100.0 & 100.0 & \\
\hline
\end{tabular}

I am a competent add to this organization

\begin{tabular}{|ll|l|l|l|l|}
\hline & Frequency & Percent & Valid Percent & Cumulative Percent \\
\hline Valid & strongly agree & 231 & 60.0 & 60.0 & 60.0 \\
& agree & 147 & 38.2 & 38.2 & 98.2 \\
& neutral & 7 & 1.8 & 1.8 & 100.0 \\
Total & 385 & 100.0 & 100.0 & \\
\hline
\end{tabular}

The organisation's performance is excellent

\begin{tabular}{|ll|l|l|l|l|}
\hline & Frequency & Percent & Valid Percent & Cumulative Percent \\
\hline Valid & strongly agree & 102 & 26.5 & 26.5 & 26.5 \\
& agree & 252 & 65.4 & 65.4 & 91.9 \\
& neutral & 31 & 8.1 & 8.1 & 100.0 \\
Total & 385 & 100.0 & 100.0 & \\
\hline
\end{tabular}

Job allows me to make use of my full potential

\begin{tabular}{|ll|l|l|l|l|}
\hline & Frequency & Percent & Valid Percent & Cumulative Percent \\
\hline Valid & strongly agree & 49 & 12.7 & 12.7 & 12.7 \\
& agree & 224 & 58.2 & 58.2 & 70.9 \\
& neutral & 98 & 25.5 & 25.5 & 96.4 \\
disagree & 14 & 3.6 & 3.6 & 100.0 \\
Total & 385 & 100.0 & 100.0 & \\
\hline
\end{tabular}

Financial incentives motivates me to perform at work

\begin{tabular}{|ll|l|l|l|l|}
\hline & Frequency & Percent & Valid Percent & Cumulative Percent \\
\hline Valid & strongly agree & 151 & 39.2 & 39.2 & 39.2 \\
& agree & 217 & 56.4 & 56.4 & 95.6 \\
& neutral & 14 & 3.6 & 3.6 & 99.2 \\
disagree & 3 & .8 & .8 & 100.0 \\
Total & 385 & 100.0 & 100.0 & \\
\hline
\end{tabular}

Salary and its subsequent increments that are provided motivates me to meet my target

\begin{tabular}{|ll|l|l|l|l|}
\hline & Frequency & Percent & Valid Percent & Cumulative Percent \\
\hline Valid & strongly agree & 147 & 38.2 & 38.2 & 38.2 \\
& Agree & 231 & 60.0 & 60.0 & 98.2 \\
& Neutral & 4 & 1.0 & 1.0 & 99.2 \\
Disagree & 3 & .8 & .8 & 100.0
\end{tabular}


Salary and its subsequent increments that are provided motivates me to meet my target

\begin{tabular}{|ll|l|l|l|l|}
\hline & Frequency & Percent & Valid Percent & Cumulative Percent \\
\hline Valid & strongly agree & 147 & 38.2 & 38.2 & 38.2 \\
& Agree & 231 & 60.0 & 60.0 & 98.2 \\
& Neutral & 4 & 1.0 & 1.0 & 99.2 \\
Disagree & 3 & .8 & .8 & 100.0 \\
Total & 385 & 100.0 & 100.0 & \\
\hline
\end{tabular}

The benefit packages I receive motivates me

\begin{tabular}{|ll|l|l|l|l|}
\hline & Frequency & Percent & Valid Percent & Cumulative Percent \\
\hline Valid & strongly agree & 119 & 30.9 & 30.9 & 30.9 \\
& agree & 252 & 65.5 & 65.5 & 96.4 \\
& neutral & 11 & 2.8 & 2.8 & 99.2 \\
disagree & 3 & .8 & .8 & 100.0 \\
Total & 385 & 100.0 & 100.0 & \\
\hline
\end{tabular}

The possibility of getting a promotion motivates me to do my best at work

\begin{tabular}{|ll|l|l|l|l|}
\hline & Frequency & Percent & Valid Percent & Cumulative Percent \\
\hline Valid & strongly agree & 158 & 41.0 & 41.0 & 41.0 \\
& agree & 214 & 55.6 & 55.6 & 96.6 \\
& neutral & 13 & 3.4 & 3.4 & 100.0 \\
Total & 385 & 100.0 & 100.0 & \\
\hline
\end{tabular}

Achieving recognition and credits motivates me at work

\begin{tabular}{|ll|l|l|l|l|}
\hline & & & & Cumulative \\
& & Frequency & Percent & Valid Percent & Percent \\
\hline Valid & strongly agree & 126 & 32.7 & 32.7 & 32.7 \\
& agree & 231 & 60.0 & 60.0 & 92.7 \\
& neutral & 25 & 6.5 & 6.5 & 99.2 \\
& strongly disagree & 3 & .8 & .8 & 100.0 \\
Total & 385 & 100.0 & 100.0 & \\
\hline
\end{tabular}

The drive of gaining more skills at my job motivates me

\begin{tabular}{|ll|l|l|l|l|}
\hline & Frequency & Percent & Valid Percent & Cumulative Percent \\
\hline Valid & strongly agree & 161 & 41.8 & 41.8 & 41.8 \\
& agree & 221 & 57.4 & 57.4 & 99.2 \\
& disagree & 3 & .8 & .8 & 100.0 \\
Total & 385 & 100.0 & 100.0 & \\
\hline
\end{tabular}

The desire to work in this organisation motivates me to improve in my performance

\begin{tabular}{|l|l|l|l|l|}
\hline & Frequency & Percent & Valid Percent & Cumulative Percent \\
\hline Valid_strongly agree & 74 & 19.2 & 19.2 & 19.2
\end{tabular}




\begin{tabular}{|l|l|l|l|l|}
\hline agree & 242 & 62.9 & 62.9 & 82.1 \\
neutral & 60 & 15.6 & 15.6 & 97.7 \\
disagree & 9 & 2.3 & 2.3 & 100.0 \\
Total & 385 & 100.0 & 100.0 & \\
\hline
\end{tabular}

Non-financial incentives motivates me to perform well at work

\begin{tabular}{|ll|l|l|l|l|}
\hline & & & & Cumulative \\
& & Frequency & Percent & Valid Percent & $\begin{array}{l}\text { Percent } \\
\text { Valid }\end{array}$ strongly agree \\
& 42 & 10.9 & 10.9 & 10.9 \\
& agree & 217 & 56.4 & 56.4 & 67.3 \\
& neutral & 77 & 20.0 & 20.0 & 87.3 \\
& disagree & 35 & 9.1 & 9.1 & 96.4 \\
& strongly disagree & 14 & 3.6 & 3.6 & 100.0 \\
Total & 385 & 100.0 & 100.0 & \\
\hline
\end{tabular}

I am satisfied with the incentives the bank offers

\begin{tabular}{|ll|l|l|l|l|}
\hline & & & & Cumulative \\
& & Frequency & Percent & Valid Percent & Percent \\
\hline Valid & strongly agree & 18 & 4.7 & 4.5 & 4.7 \\
& agree & 182 & 47.3 & 47.3 & 52 \\
& neural & 126 & 32.7 & 32.7 & 84.7 \\
& disagree & 46 & 11.9 & 11.8 & 96.6 \\
& strongly disagree & 13 & 3.4 & 3.6 & 100.0 \\
Total & 385 & 100.0 & 100.0 & \\
\hline
\end{tabular}

Organization performance has been tremendous over the years with increase in customer base and profit

\begin{tabular}{|ll|l|l|l|l|}
\hline & & & & Cumulative \\
& & Frequency & Percent & Valid Percent & Percent \\
\hline Valid & strongly agree & 140 & 36.4 & 36.4 & 36.4 \\
& agree & 210 & 54.5 & 54.5 & 90.9 \\
& neutral & 28 & 7.3 & 7.3 & 98.2 \\
& disagree & 7 & 1.8 & 1.8 & 100.0 \\
Total & 385 & 100.0 & 100.0 & \\
\hline
\end{tabular}

The good working condition provided at work motivates me

\begin{tabular}{|ll|l|l|l|l|}
\hline \multicolumn{2}{|c|}{} & Frequency & Percent & Valid Percent & Cumulative Percent \\
\hline Valid & strongly agree & 137 & 35.6 & 35.6 & 35.6 \\
& agree & 242 & 62.8 & 62.8 & 98.4 \\
& neutral & 6 & 1.6 & 1.6 & 100.0 \\
& Total & 385 & 100.0 & 100.0 & \\
\hline
\end{tabular}

\section{Statistics}

\begin{tabular}{|c|c|c|c|c|}
\hline & Gender & Qualifications & $\begin{array}{l}\text { The duration of } \\
\text { working at the } \\
\text { bank }\end{array}$ & Work level \\
\hline $\begin{array}{ll}\mathrm{N} & \text { Valid }\end{array}$ & 385 & 385 & 385 & 385 \\
\hline
\end{tabular}


International Journal of Entrepreneurial Knowledge

Issue 2/2016, Volume 4

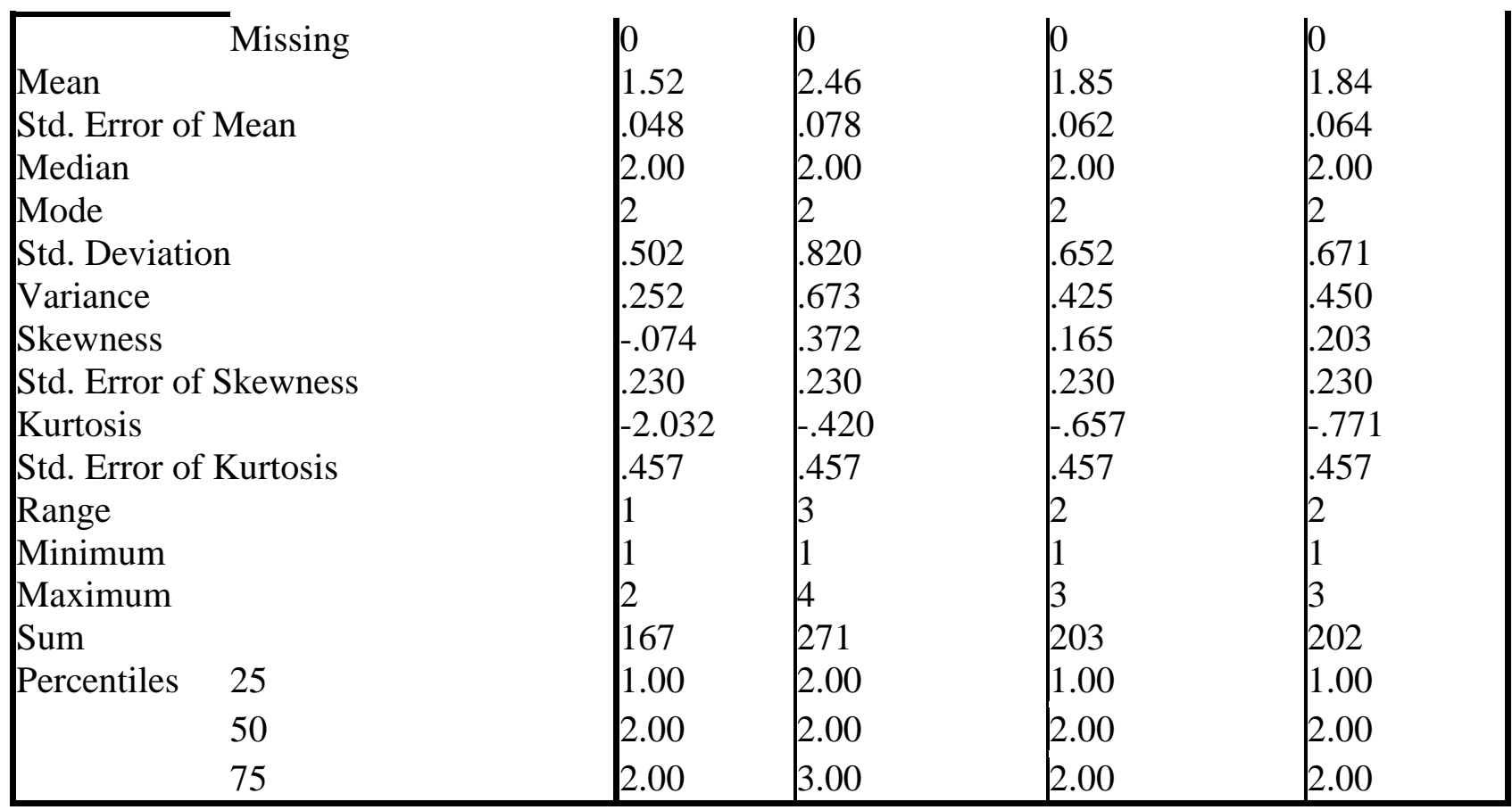

2.

Reliability Statistics 1

Reliability Test

\begin{tabular}{|l|l|l|}
\hline Cronbach's Alpha & $\begin{array}{l}\text { Cronbach's Alpha Based on } \\
\text { Standardized Items }\end{array}$ & N of Items \\
\hline .736 & .704 & 7 \\
\hline
\end{tabular}

\begin{tabular}{|l|l|l|l|}
\hline Item Statistics & Mean & Std. Deviation & N \\
\hline $\begin{array}{l}\text { The job description and specifications were clearly } \\
\text { defined in the recruitment process }\end{array}$ & & .22 & 385 \\
The job position was what I expected & & \\
The recruitment process and selection influenced my & 2.43 & .953 & 385 \\
performance at work & .865 & 385 \\
I am a competent add to this organisation & & \\
The organisation's performance is excellent & 1.42 & .531 & 385 \\
The job position I currently hold allow me make use of & 2.35 & .561 & 385 \\
my full potentials & & 1.001 & 385 \\
I feel highly motivated at work & & \\
\hline
\end{tabular}

\section{Item-Total Statistics}

\begin{tabular}{|l|l|l|l|l|l|}
\hline & $\begin{array}{l}\text { Scale Mean if } \\
\text { Item Deleted }\end{array}$ & $\begin{array}{l}\text { Scale } \\
\text { Variance if } \\
\text { Item Deleted }\end{array}$ & $\begin{array}{l}\text { Corrected } \\
\text { Item-Total } \\
\text { Correlation }\end{array}$ & $\begin{array}{l}\text { Squared } \\
\text { Multiple } \\
\text { Correlation }\end{array}$ & $\begin{array}{l}\text { Cronbach's } \\
\text { Alpha if Item } \\
\text { Deleted }\end{array}$ \\
\hline $\begin{array}{l}\text { The job description and } \\
\text { specifications were } \\
\text { clearly defined in the } \\
\text { recruitment process } \\
\begin{array}{l}\text { The job position was } \\
\text { what I expected }\end{array}\end{array}$ & 8.508 & .575 & .468 & .672 \\
\hline
\end{tabular}


International Journal of Entrepreneurial Knowledge

Issue 2/2016, Volume 4

The recruitment process 12.44

and selection influenced

my performance at work

I am a competent add to 13.33

this organisation

The organisation's 12.93

performance is excellent

The job position I 12.39

currently hold allow me

make use of my full

potentials

I feel highly motivated 12.55

$9.257 \quad .416$

206

.713

at work

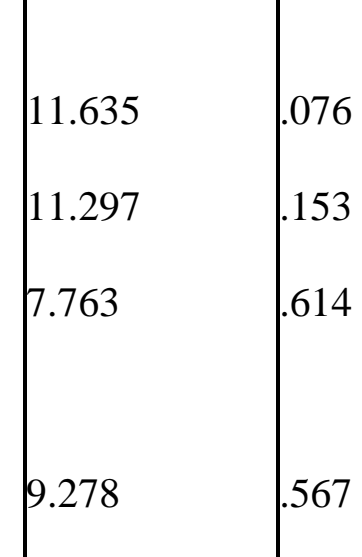

.764
.755
.658
.681

.397

Reliability Statistics 2

\begin{tabular}{|l|l|l|}
\hline Cronbach's Alpha & $\begin{array}{l}\text { Cronbach's Alpha Based on } \\
\text { Standardized Items }\end{array}$ & N of Items \\
\hline 707 & .751 & 11 \\
\hline
\end{tabular}

\begin{tabular}{|l|l|l|l|}
\hline & Mean & Std. Deviation & N \\
\hline Financial incentives motivates me to perform at work & 1.66 & .595 & 385 \\
Salary and its subsequent increments that are provided motivates & 1.65 & .552 & 385 \\
me to meet my target & & & \\
The benefit packages I receive motivates me & 1.74 & .553 & 385 \\
My morale affects my performance at work & 1.75 & .670 & 385 \\
The possibility of getting a promotion motivates me to do my best & 1.63 & .556 & 385 \\
at work & 1.76 & .649 & 385 \\
Achieving recognition and credits motivates me at work & 1.66 & .512 & 385 \\
The good working condition provided at work motivates me & 1.60 & .545 & 385 \\
The drive of gaining more skills at my job motivates me & .677 & 385 \\
The desire to work in this organisation motivates me to improve in & 2.02 & .82 & 385 \\
my performance & 2.63 & .887 & 385 \\
Iam satisfied with the incentives the bank offers & 2.38 & .928 & \\
Non-financial incentives motivates me to perform well at work & & & \\
\hline
\end{tabular}

\begin{tabular}{|c|c|c|c|c|c|}
\hline \multicolumn{6}{|l|}{ Item- Total statistics } \\
\hline & $\begin{array}{l}\text { Scale Mean if } \\
\text { Item Deleted }\end{array}$ & $\begin{array}{l}\text { Scale } \\
\text { f } \begin{array}{l}\text { Variance } \\
\text { Item Deleted }\end{array}\end{array}$ & $\begin{array}{l}\text { Corrected } \\
\text { iff Item-Total } \\
\text { Correlation } \\
\end{array}$ & \begin{tabular}{|l} 
Squared \\
Multiple \\
Correlation \\
\end{tabular} & \begin{tabular}{|l|} 
Cronbach's \\
Alpha if Item \\
Deleted
\end{tabular} \\
\hline $\begin{array}{l}\text { Financial incentives } \\
\text { motivates me to perform } \\
\text { at work }\end{array}$ & 18.81 & 12.138 & .230 & .683 & .703 \\
\hline
\end{tabular}




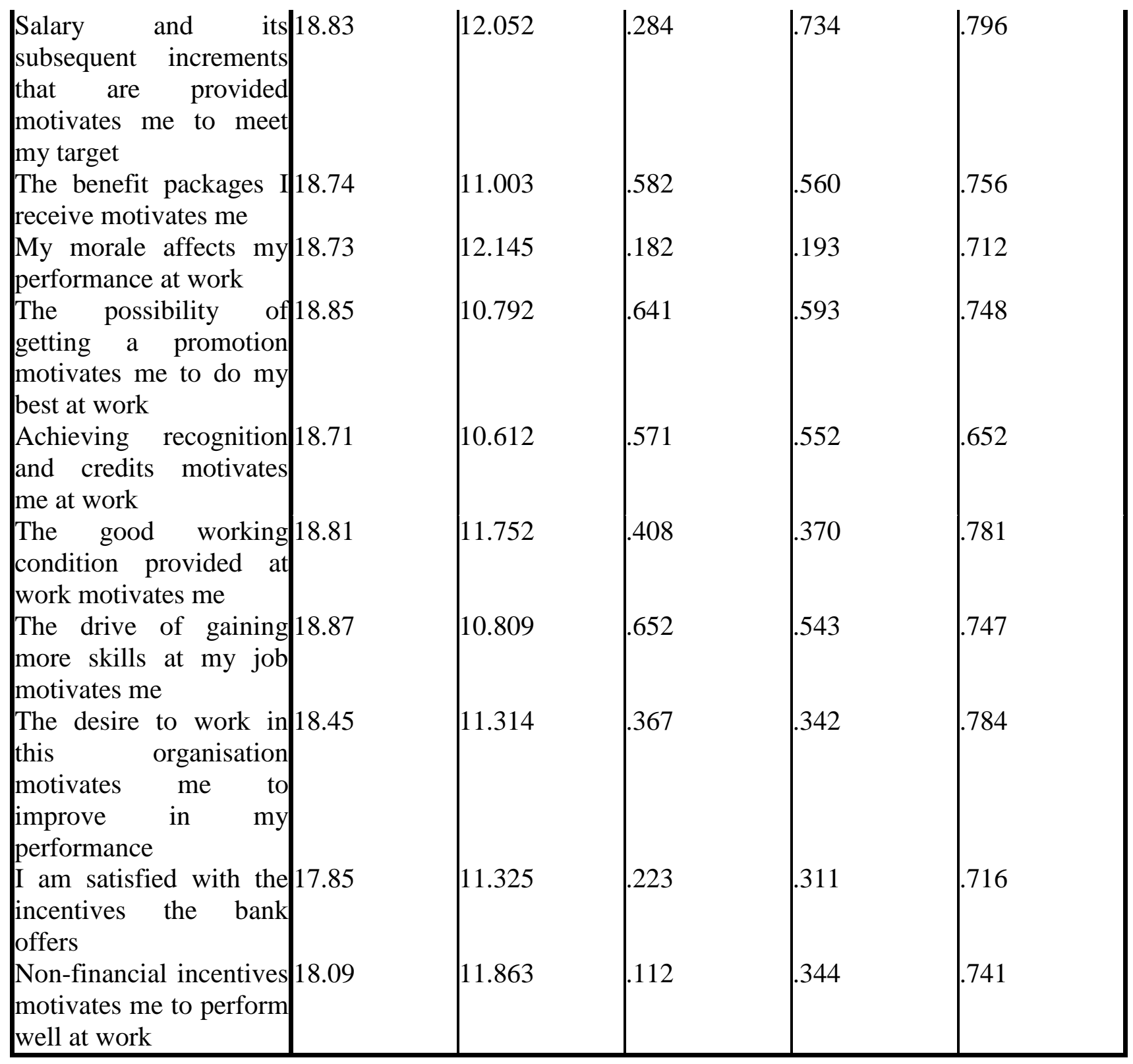

3. Correlation Analysis for the test of the Core Hypothesis

\begin{tabular}{|c|c|c|c|c|}
\hline & & Performance & EM & Recruitment \\
\hline Performance & $\begin{array}{l}\text { Pearson Correlation } \\
\text { Sig. (2-tailed) } \\
\text { N }\end{array}$ & 385 & $\begin{array}{l}.468^{* *} \\
.000 \\
385 \\
\end{array}$ & $\begin{array}{l}.505^{* *} \\
.000 \\
385\end{array}$ \\
\hline EM & $\begin{array}{l}\text { Pearson Correlation } \\
\text { Sig. (2-tailed) } \\
\mathrm{N} \\
\end{array}$ & $\begin{array}{l}.468^{* *} \\
000 \\
385 \\
\end{array}$ & 385 & $\begin{array}{l}.600^{* *} \\
.000 \\
385 \\
\end{array}$ \\
\hline Recruitment & $\begin{array}{l}\text { Pearson Correlation } \\
\text { Sig. (2-tailed) } \\
\mathrm{N}\end{array}$ & $\begin{array}{l}.505^{* *} \\
.000 \\
385\end{array}$ & $\begin{array}{l}.600^{* * *} \\
.000 \\
385\end{array}$ & $\begin{array}{l}1 \\
385\end{array}$ \\
\hline
\end{tabular}

**. Correlation is significant at the 0.01 level (2-tailed).

\begin{tabular}{|ll|l|l|}
\hline & EMRP & Performance \\
\hline EMRP & Pearson Correlation & 1 & $.590^{* *}$
\end{tabular}




\begin{tabular}{|c|c|c|c|}
\hline & $\begin{array}{l}\text { Sig. (2-tailed) } \\
\mathrm{N}\end{array}$ & 385 & $\mid \begin{array}{l}.000 \\
385\end{array}$ \\
\hline Performance & $\begin{array}{l}\text { Pearson Correlation } \\
\text { Sig. (2-tailed) } \\
\mathrm{N}\end{array}$ & $\begin{array}{l}.590^{* * *} \\
.000 \\
385\end{array}$ & 1 \\
\hline
\end{tabular}

**. Correlation is significant at the 0.01 level (2-tailed). 